\title{
Karakteristik Morfologis Dan Reproduksi Kerbau Pampangan Di Propinsi Sumatera Selatan
}

\author{
Muhakka, Riswandi dan Asep Indra M. Ali \\ Program Studi Peternakan Fakultas Pertanian Universitas Sriwijaya \\ Telp. 0711581106, HP: 08153808409, 081367755499, e-mail: muhakka@yahoo.co.id
}

\begin{abstract}
ABSTRAK
Penelitian ini bertujuan untuk mengetahui karakteristik morfologis dan reproduksi kerbau pampangan di Propinsi Sumatera Selatan. Dilaksanakan di tiga kabupaten yaitu kabupaten OKI, Banyuasin dan Ogan Ilir selama 6 bulan. Metode yang digunakan adalah metode survei. Penarikan contoh bersifat multistage purposive sampling mulai dari penentuan kabupaten, kecamatan, serta peternak. Setelah ditetapkan tiga kabupaten lokasi sampel, akan dipilih masing-masing satu kecamatan sentra populasi yang jumlah populasinya terbanyak. Data yang dikumpulkan meliputi data primer dan data sekunder. Data yang diperoleh diolah secara matematis, disajikan secara tabulasi kemudian dijelaskan secara deskriptif, yaitu melukiskan secara sistematis fakta atau karakteristik morfologis dan reproduksi kerbau pampangan secara cermat dan faktual dari data yang telah terkumpulkan. Karakteristik morfologis kerbau pampangan adalah warna bulu hitam/hitam keabu-abuan, bentuk tubuh besar, temperamen tenang, kepala besar dan telinga panjang, tanduk ada yang tegak panjang dan melingkar ke arah belakang dan ada juga yang arah ke bawah. Bentuk ambing simetris dan berkembang dengan baik. Karakteristik reproduksi kerbau Pampangan umur pertama kawin rata-rata 2,3 tahun atau 27 bulan, umur beranak pertama 3,23 tahun, estrus (berahi) pertama setelah beranak 88,33 hari, kawin setelah beranak 139,11 hari, jarak beranak 14 bulan dan umur lepas sapih anak 9,07 bulan.
\end{abstract}

Kata kunci: Karakteristik, morfologis, reproduksi, kerbau

PENDAHULUAN

Latar Belakang

Di Sumatera Selatan, banyak ditemukan ternak kerbau yang hidup di daerah rawa lebak terutama di Desa
Pulau Layang Kecamatan Pampangan Kabupaten Ogan Komering Ilir (OKI) dan di Desa Rambutan Kecamatan Rambutan Kabupaten Banyuasin, Di Desa Talang Pangeran Ulu Kecamatan 
Pemulutan Kabupaten Ogan Ilir yang dikenal dengan Kerbau Pampangan yang merupakan salah satu kekayaan plasma nutfah di Sumatera Selatan. Selain diambil dagingnnya, kerbau Pampangan dikenal juga sebagai penghasil susu.

Plasma nutfah merupakan bahan genetik yang memiliki nilai guna, baik secara nyata maupun yang masih berupa potensi. Wilayah Indonesia yang membentang luas dengan kondisi geografis dan ekologi yang bervariasi telah menciptakan keanekaragaman plasma nutfah yang sangat tinggi. Dengan keanekaragaman plasma nutfah, terbuka peluang yang besar bagi upaya program pemuliaan guna memperoleh manfaat secara optimal (Kurniawan et al., 2004).

Untuk mengurangi atau bahkan mencegah terjadinya erosi genetik yang makin meningkat terhadap plasma nutfah, maka perlu perhatian yang besar terhadap plasma nutfah yang ada terutama varietasvarietas lokal baik tanaman maupun hewan. Perhatian diberikan dalam bentuk kegiatan inventarisasi (koleksi), pendataan (dokumentasi) dan pelestarian (konservasi). Guna meningkatkan nilai gunanya perlu diikuti dengan upaya identifikasi karakter penting melalui kegiatan karakterisasi dan evaluasi secara sistematis dan berkelanjutan seperti melalui seleksi maupun rakayasa genetik agar dapat dimanfaatkan (Handoyo, 2005).

Akibat perkawinan silang ternak lokal dengan ternak-ternak impor yang dilaksanakan tanpa rencana dan evaluasi yang mantap, akan menyebabkan keragaman gen di dalam bangsa dan antara bangsa ternak. Ternak-ternak lokal telah mengalami seleksi alam dan buatan oleh manusia setempat dan telah beradaptasi dengan baik terhadap lingkungannya. Sifat daya adaptasi ternak lokal yang baik terhadap lingkungan alamnya menjadi berkurang dikarenakan persilangan dengan bangsa-bangsa ternak lain, sedangkan untuk meningkatkan mutu genetik ternak-ternak lokal kurang sekali dilakukan (Hardjosworo, 1985).

Daya tahan umumnya sudah dimiliki oleh ternak-ternak lokal setempat dan daya tahan ternakternak lokal ini berkurang oleh pengaruh persilangan dengan ternakternak impor dari daerah lain. Untuk itu diperlukan suatu upaya untuk mempertahankan dan melestarikan ternak-ternak lokal ini secara murni dan meneliti tentang gen-gen unik yang dimiliki (Mansjoer, 1985).

Kerbau Pampangan dipelihara secara tradisional, yaitu pada malam hari dikandangkan secara berkelompok, sedangkan pada siang hari dilepas-gembalakan di daerah rawa-rawa. Populasi ternak ini dari tahun ke tahun terus mengalami 
penurunan. Hingga saat ini populasi ternak ini diperkirakan hanya tinggal 3.623 ekor. Permasalahan lain minimnya tata laksana pemeliharaan mengakibatkan terjadinya inbreeding, sehingga akan mengakibatkan penurunan potensi genetik Kerbau Pampangan.

Data mengenai potensi karakteristik morfologis dan reproduksi Kerbau Pampangan belum pernah dilaporkan, sehingga keunggulan dan kelemahan potensi kerbau pampangan belum diketahui. Hal ini disebabkan karena tidak tersedianya data untuk keperluan analisis potensi karakteristik morfologis dan reproduksi karena sistem identifikasi dan recording ternak tidak pernah dilakukan. Oleh karena itu perlu dilakukan penelitian tentang karakteristik morfologis dan reproduksi kerbau pampangan di Sumatera Selatan.

\section{Tujuan Penelitian}

Untuk mengetahui

karakteristik morfologis dan reproduksi kerbau pampangan di Propinsi Sumatera Selatan.

\section{METODE PENELITIAN}

Penelitian dilaksanakan di tiga kabupaten di Propinsi Sumatera Selatan dengan penekanan pada kabupaten yang memiliki kerbau rawa yang cukup banyak, yakni Kabupaten Ogan Komering Ilir
(Kecamatan Pampangan) Banyuasin (Kecamatan Rambutan) dan Ogan Ilir (Kecamatan Pemulutan). Lama penelitian selama 6 bulan, dari bulan Juli-Desember 2012. Metode yang digunakan adalah metode survei. Penarikan contoh bersifat multistage purposive sampling mulai dari penentuan kabupaten, kecamatan, serta peternak. Setelah ditetapkan tiga kabupaten lokasi sampel, langkah selanjutnya akan dipilih masingmasing satu kecamatan sentra populasi yang jumlah populasinya terbanyak.

Data yang dikumpulkan meliputi data primer dan data sekunder. Data yang diperoleh di lapangan kemudian diolah secara matematis, disajikan secara tabulasi kemudian dijelaskan secara deskriptif, yaitu melukiskan secara sistematis fakta atau karakteristik morfologis dan reproduksi kerbau pampangan secara cermat dan faktual dari data yang telah terkumpulkan

\section{HASIL DAN PEMBAHASAN}

\section{Keadaan Umum Peternak Kerbau Pampangan}

Keadaan umum peternak ketiga desa yang dijadikan tempat penelitian study karakteristik kerbau pampangan yang merupakan ketiga kabupaten yaitu Kabupaten OKI, Banyuasin Ogan Ilir Sumatera Dari data statistik ke tiga desa tersebut, mata pencaharian utama 
masyarakatnya adalah sangat bervariasi, namun sebagian besar adalah petani $(70,46 \%)$, peternak $(15,91 \%)$, Pedagang $(6,82 \%)$, swasta $(2,27 \%)$, POLRI $(2,27 \%)$ dan sopir $(2,27 \%)$ dan tiap-tiap kepala keluarga memelihara ternak sebagai usaha sampingan seperti sapi, kerbau dan kambing.

Karakteristik peternak menunjukkan bahwa usia peternak yang masih produksif atau usia mereka masih muda dengan rata-rata umur pternak 40,12 tahun dengan usia termuda 18 tahun dan usia tertua 62 tahun, dengan pengalaman (lama) beternak kerbau rata-rata 12,47 tahun dengan skala pengalaman beternak dari 2 tahun sampai dengan 40 tahun.

Berdasarkan datastatistik, pada umumnya tingkat pendidikan peternak kerbau adalah sebagai berikut dimana Sekolah Dasar (55,56\%), SMP $(31,11 \%)$ dan tingkat SMA/sederajat hanya (13,33\%). Hasil diskusi dengan peternak menunjukkan bahwa minat peternak untuk mengembangkan ternak ternak kerbau cukup besar, hal ini ditandai dengan aktifnya menanyakan bagaimana cara mendapatkan bantuan kerbau dari pemerintah, bagaimana sistem beternak kerbau yang baik dan masalah utama yang dihadapi oleh peternak dalam mengelola usaha ternak kerbau adalah terbatasnya tingkat pengetahuan beternak kerbau yang baik, baik ditinjau dari segi penyediaan pakan (rumput unggul), pengolahan pakan, khususnya pengolahan limbah pertanian/perkebunan sebagai sumber pakan ternak, perkandangan maupun dari segi pencegahan penyakit, lemahnya permodalan dan kelembagaan kelompok usaha yang ada.

\section{Karakteristik Morfologis Kerbau} Pampangan

Di Sumatera Selatan (Sumsel), banyak ditemukan ternak kerbau yang hidup di daerah rawa lebak terutama di Kec. Pampangan, Kab. Ogan Komering Ilir (OKI) yang dikenal dengan Kerbau Pampangan yang merupakan salah satu kekayaan plasma nutfah di Sumsel. Selain diambil dagingnnya, kerbau Pampangan dikenal juga sebagai penghasil susu. Kerbau Pampangan umumnya dipelihara secara ektensif dimana pada siang hari dilepaskan di padang penggembalaan dan pada malam harinya

di kandangkan.Perkembangan populasi kerbau Pampangan di Sumatera Selatan dari 2010 hingga 2011 terjadi penurunan yaitu dari 76.113 menjadi 29.143 ekor (- 61,7\%). Penurunan populasi kerbau Pampangan ini disebabkan beberapa faktor, diantaranya jumlah pemotongan yang terus meningkat dan lebih tinggi dibandingkan penambahan populasi, disamping kuranmgnya perhatian terhadap ternak kerbau, menurunnya lahan untuk padang penggembalaan. 
Selain itu secara alamiah kerbau memiliki tingkat reproduksi yang rendah (Barile, 2005; De Rensis dan Lopes-Gatius, 2007; Perera, 2011).

Populasi ternak kerbau tersebar di Kabupaten OKI (5.286 ekor), Banyuasin (1.843 ekor) dan Ogan Ilir (1.727 ekor). Sebagian besar kerbau tersebut dipelihara di Desa Pulau Layang OKI, Rambutan Banyuasi dan Talang Pangeran Ulu Ogan Ilir. Dari ke-3 desa tersebut ada 44 orang peternak kerbau pampangan yang diwawancarai dengan jumlah ternak 1.060 ekor. Peternak memelihara kerbau dengan jumlah yang bervariasi yaitu dari 4 ekor - 100 ekor, dengan tingkat kepemilikan ada yang milik sendiri dan ada yang bagi hasil. Untuk peternak kerbau dengan tingkat kepemilikan dan bagi hasil yaitu ada 29 peternak $(65,90 \%)$, milik sedndiri 10 peternak (22,73\%) dan hanya bagi hasil 5 peternak $(11,37 \%)$. Dari hasil inventarisasi diperoleh karakteristik morfologis kerbau pampangan dengan ciri-ciri sepaerti pada Gambar 1. Morfologis adalah tampilan eksternal tubuh makhluk hidup yang merupakan ekspresi dari bentuk keseimbangan biologis, sehingga dapat dipakai untuk menentukan asal-usul dan hubungan filogenekantara spesies, bangsa dan tipe ternak berbeda (Warwick et al., 1995; Drucker et al., 2011)

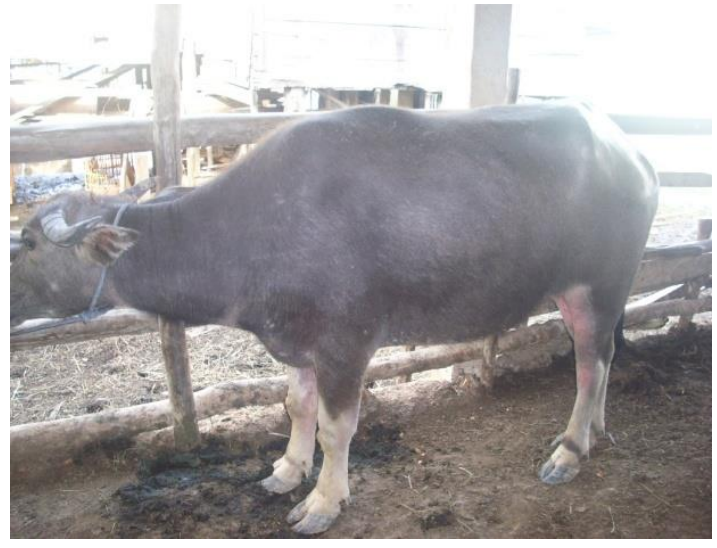

Gambar 1. Karakteristik morfologis kerbau pampangan

Adapun karakteristik morfologis kerbau pampangan di Sumatera Selatan adalah warna bulu hitam/hitam keabu-abuan, bentuk tubuh besar, temperamen tenang, kepala besar dan telinga panjang, tanduk ada yang tegak panjang dan melingkar ke arah belakang dan ada juga yang arah ke bawah. Bentuk ambing simetris dan berkembang dengan baik. Bobot badan rata-rata untuk jantan dewasa 400-450 kg dan betina dewasa 300-350 kg. Bentuk tanduk melingkar ke arah bawah atau menggantung, diduga karena telah terjadi inbreeding pada kerbau Pampangan. Menurut Sianturi et al. (2012) kerbau-kerbau di pedesaan telah terjadi inbreeding, karena kelangkaan pejantan unggul sehingga perkawinan kerbau di pedesaan sulit ditata, hal ini dapat dilihat dari meningkatnya populasi kerbau albino dan kerbau-kerbau dengan tanduk yang menggantung. 


\subsection{Karakteristik Reproduksi Kerbau Pampangan$$
\text { Rataan }
$$ \\ karakteristik \\ reproduksi ternak Kerbau}

Berdasarkan Tabel 3 di atas menunjukkan bahwa umur pertama kawin Kerbau Pampangan di Sumatera Selatan rata-rata 2,3 tahun atau 27 bulan. Ini menunjukkan bahwa kerbau pampangan sangat lamban pubertas bila dibandingkan dengan Kerbau Belang di Sulawesi Selatan. Batasomma (2004) melaporkan bahwa ternak Kerbau Belang pubertas (pertama kawin) pada umur kisaran $16-22$ bulan. Hal ini di duga karena adanya perbedaan lingkungan setempat dan manajemen pemberian pakan. Pada umumnya kerbau di Indonesia lambat mencapai dewasa kelamin dan reproduksinya serta kawin setelah beranak memerlukan waktu yang lama, sifat kurang baik ini akan bertambah lagi

Gambar 3. Rata-rata Karakteris Kerbau
Pampangan di Sumatera Selatan disajikan pada Tabel 3.

jika tidak disertai dengan manajemen pemberian pakan yang baik (Batasamma, 2004). Kondisi ini terjadi pada ternak Kerbau Pampangan di Sumatera Selatan dimana ternak kerbau hanya dipelihara secara ekstensif tanpa manajemen pemberian pakan hijauan yang berkualitas apalagi pemberian konsentrat. Kerbau dara umumnya mengalami estrus pertama kali pada kisaran umur 2 - 2,5 tahun, siklus estrusnya sama dengan sapi yaitu 21 hari, dengan kisaran 18 - 24 hari. Waktu birahi pada umumnya mempunyai kisaran 12 - 40 jam dengan rata-rata 24 jam (Mc Dowell, 1972 dalam Murti dan Ciptadi, 1988).

Umur beranak pertama Kerbau Pampangan di Sumatera Selatan ratarata 3,23 tahun, angka tersebut wajar

\begin{tabular}{ccc}
\hline No. & Karakteristik & Rataan \\
\hline 1 & Umur pertama kawin (tahun) & 2,30 \\
\hline 2 & Umur beranak pertama (tahun) & 3,23 \\
\hline 3 & strus (berahi) pertama setelah beranak (har & 88,33 \\
\hline 4 & Kawin setelah beranak (hari) & 139,11 \\
\cline { 1 - 2 } & Jarak beranak (bulan) & 14 \\
\cline { 1 - 2 } 6 & Umur sapih anak (bulan) & 9,07 \\
\hline
\end{tabular}


karena umur pertama kawin (pubertas) rata-rata 2,3 tahun, dalam artian ternak tersebut beranak pertama setelah satu tahun sejak kawin pertama. Angka ini lebih rendah bila dibandingkan hasil penelitian

Chantalakhana (1981) yang menyatakan umur beranak pertama kerbau di Indonesia berkisar 3,5 - 4,7 tahun.

Estrus (berahai) pertama setelah beranak Kerbau Pampangan rata-rata 88,33 hari, hasil tersebut menunjukkan bahwa kerbau pampangan estrus setelah beranak cukup cepat dibandingkan dengan Kerbau Belang di Sulawesi Selatan. Kerbau Belang berahi setelah beranak rata-rata 130 hari (Batasamma, 2006). Kalau dilihat dari hasil menunjukkan bahwa meskipun estrus lebih cepat setelah beranak namun estrus tersebut tidak dibarengi dengan kawin, sehingga rata-rata kawin setelah beranak 139,11 hari. Hasil ini hampir sama dengan hasil penelitian Batasamma (2004), bahwa Kerbau Belang kawin setelah beranak ratarata 130 hari pada saat terjadinya gejalah berahi. Pada Tabel 4 ditampilkan beberapa data tentang berahi (estrus) pertama setelah beranak pada beberapa jenis kerbau.

Tabel 4. Data estrus pertama setelah beranak beberapa jenis kerbau

\begin{tabular}{|c|c|c|c|}
\hline No. & Jenis dan Bangsa Kerbau & $\begin{array}{l}\text { Negara dan Tempat } \\
\text { Pengamatan }\end{array}$ & $\begin{array}{l}\text { Rata-Rata Estrus pertama setelah } \\
\text { beranak (hari) }\end{array}$ \\
\hline \multirow{5}{*}{1} & Jenis Sungai & & \\
\hline & Murrah & India & 87 \\
\hline & Murrah & India Utara & 115 \\
\hline & Murrah & Philipina & 49,6 \\
\hline & Kerbau Mesir & Mesir & 43 \\
\hline 2 & Jenis Lumpur & Philipina & 54 \\
\hline 3 & $\begin{array}{l}\text { Keturunan kawin silang } \\
\text { lumpur dengan sungai } \\
\text { (Murrah Philipina) }\end{array}$ & Philipina & 45,8 \\
\hline
\end{tabular}

Sumber : Fahimudin, M. (1975) dalam Murti dan Ciptadi, 1988). 
Berdasarkan Tabel 4 di atas menunjukkan bahwa rata-rata estrus setelah beranak Kerbau Murrah dari India 87 hari, data tersebut hampir sama dengan hasil yang diperoleh bahwa estrus pertama setelah beranak Kerbau Pampangan rata-rata 88,33 hari. Hasil tersebut diduga bahwa Kerbau Pampangan asal-usulnya berasal dari India atau kerbau silangan atau keturunannya.

Berdasarkan Tabel 3 di atas menunjukkan bahwa jarak beranak/jarak kelahiran Kerbau Pampangan rata-rata 14 bulan atau 420 hari, hasil tersebut sesuai dengan hasil penelitian Chantalakhana (1981) yang menyatakan bahwa jarak beranak kerbau di Indonesia berkisar 370 - 670 hari. Kerbau Belang jarak beranak (calving interval) rata-rata 400 - 600 hari (Batosamma, 2004). Kerbau betina umumnya beranak pertama kali pada umur 4 tahun dengan lama kebuntingan 10,5 bulan. Bila pakannya cukup memadai maka 3-4 bulan setelah melahirkan induk kerbau biasanya sudah dapat dikawinkan lagi. Sebagian peternak melaporkan jarak beranak selama 14 bulan. Namun umumnya ditemui bahwa usia kebuntingan induk sekitar dua bulan pada saat anak sudah berumur setahun. Dengan demikian jarak beranak menjadi 21 bulan. Hal ini menunjukkan bahwa tingkat reproduksi kerbau hanya mencapai $60 \%$. Apabila dikelola dengan baik maka jarak beranak dapat dipersingkat lagi, terutama dengan penyediaan pakan yang memadai bagi kebutuhan induk dan bagi produksi susunya (Permentan, 2006).

Kegagalan perkawinan akan menambah panjang jarak antar satu kelahiran dengan kelahiran berikutnya. Kerbau India - Pakistan rata-rata mempunyai jarak kelahiran satu anak dengan anak berikutnya sekitar 450 hari, kerbau Mesir 540 hari, kerbau rawa Philipina 535 hari, kerbau hasil perkawinan silang Murrah dengan rawa Philipina 429,2 hari dan kerbau keturunan ke-3 dan ke-4 perkawinan silang antara kerbau rawa Thailand dengan kerbau Murrah adalah 287 - 420 hari. Secara umum dapat digolongkan dalam kelompok berdasarkan jenis kerbaunya bahwa kerbau lumpur mempunyai kisaran jarak satu kelahiran dengan kelahiran berikutnya 480 - 912 hari, kerbau sungai 450 - 580 hari dan persilangan keduanya lebih kurang 344 hari (Tumwasorn, 1984 dalam Murti dan Ciptadi, 1988). Adanya perbedaan jarak beranak (calving interval) kerbau tersebut diduga karena adanya perbedaan genetik (bangsa) dan lingkungan. Meskipun perbedaan pengharuh genetik hanya sekitar 30\% dan yang paling besar porsinya lingkungan $70 \%$.

Umur sapih anak Kerbau Pampangan di Sumatera Selatan ratarata 9,07 bulan. Hasil tersebut tegolong cukup tinggi bila dibandingkan pada ternak sapi yang kisarannya 4,89 - 7,83 bulan (Astuti, 2004). Tingginya umur sapih karena sistem pemeliharaan pada ternak kerbau dilakukan secara ekstensif. Dimana ternak hanya 
dibiarkan mencari pakan sendiri di padang penggembalaan, sehingga anak kerbau selalu tergantung dan mengikuti induknya di padang penggembalaan.

\section{KESIMPULAN DAN SARAN \\ Kesimpulan}

Karakteristik morfologis

Kerbau Pampangan di Sumatera Selatan adalah warna bulu hitam/hitam keabu-abuan, bentuk tubuh besar, temperamen tenang, kepala besar dan telinga panjang, tanduk ada yang tegak panjang dan melingkar ke arah belakang dan ada juga yang arah ke bawah. Bentuk ambing simetris dan berkembang dengan baik. Bobot badan rata-rata untuk jantan dewasa 400-450 kg dan betina dewasa 300-350

Karakteristik reproduksi

kerbau Pampangan di Sumatera

Selatan umur pertama kawin rata-rata

2,3 tahun atau 27 bulan, umur

beranak pertama 3,23 tahun, estrus

(berahi) pertama setelah beranak

88,33 hari, kawin setelah beranak

139,11 hari, jarak beranak 14 bulan

dan umur lepas sapih anak 9,07

bulan.

\section{Saran}

Untuk

meningkatkan

karakteristik reproduksi Kerbau Pampangan, maka perlu dilakukan perbaikan sistem pemeliharaan terutama manajemen pemberian pakan pada musim kemarau.

\section{DAFTAR PUSTAKA}

Astuti, M. 2004. Potensi dan keragaman sumberdaya genetik sapi peranakan ongole (PO). Lokakarya Nasional Sapi Potong.

Balai Pengkajian Teknologi Pertanian Sumatera Selatan, 2011. Kerbau pampangan sebagai Plasma Nutfah Sumatera Selatan. bptpsumsel@litbang.deptan.go.id

Barile, V.L. 2005. Improving reproductive efficiency in female buffaloes. Liv. Reprod. Sci. 92: 183-194.

Batosamma, T. 2004. Potensi dan Prospek Pengembangan Kerbau Belang di Sulawesi Selatan. Makalah disampaikan pada Seminar dan Lokakarya Nasional Peningkatan Populasi dan Produktivitas Ternak Kerbau di Indonesia. Banjarmasin,7-8 Desember 2004.

Batosamma, T. 2006. Potential and application of reproduction technologies of water buffaloes in Indonesia. International Seminar on Artificial Reproductive Biotechnologies for Buffaloes, Bogor, August 28 - September 01.

De Rensis, F. and F. Lopez-Gatius. $2007 . \quad$ Protocolsfor synchronizing estrus and ovulation in buffalo (Bubalus bubalis): A review. Theriogenelogy 67:209-216. 
Dinas Peternakan dan Perikanan Kab. Banyuasin. 2011. Populasi ternak menurut jenis. Dinas Peternakan dan Perikanan Kab. Banyuasin. 2011.

Dinas Peternakan dan Perikanan Kab. OKI. 2011. Populasi ternak menurut jenis. Dinas Peternakan dan Perikanan Kab. OKI.

Drucker, A.G, V. Gomez an S. Anderson. 2001. The economic valuation of farm animal genetic resources: A survey of available methods. Ecol. Econ. 36:1-18.

Hardjosworo, P.S. 1985. Konservasi

Ternak Asli.Fakultas

Peternakan. IPB. Bogor

Handoyo. J., Sherly Sisca dan Mastutiningsih. 2005. Sekilas Keragaman Hayati di Jawa Tengah. Warta Plasma Nutfah Indonesia. No.17.

Kurniawan, Ida Haranida. S, Hadiatmi dan Asadi. 2004. KATALOG DATA PASPOR PLASMA Nutfah Tanaman Pangan. Balai Besar Penelitian dan Pengembangan Bioteknologi dan Sumberdaya Genetik Pertanian. Bogor.
Mansjoer, S.S. 1985. Pengkajian sifatsifat produksi ayam kampung serta persilangannya dengan ayam Rhode Island Red. Disertasi. Fakultas Pascasarjana IPB. Bogor.

Murti, T.W., G. Ciptadi. 1988. Kerbau Perah dan Kerbau Kerja. Tatalaksana dan Pengetahuan Dasar Pasca Panen. PT. Mediyatama Sarana Perkasa, Jakarta.

Perera, B.M.A.O. 2011.Reproductive cycles of Buffallo. Anim. Reprod. Sci. 124:194-199.

Permentan.2006. Tentang Pedoman Pembibitan Kerbau yang Baik (Good Breeding Practice).

Sianturi, R.G., B. Purwantara, I. Supriatna, Amrozi dan P. Situmorang. 2012. Optimasi Inseminasi Buatan pada kerbau lumpur (Bubalus bubalis) melalui teknik sinkronisasi estrus dan ovulasi.Jur. Ilmu Ternak dan Veteriner. 17:92-99. Warwck, E.J., J.M. Astuti dan W. Hardjosubroto. 1995. Pemuliaan Ternak. Gadjah Mada University. Press, Yogyakarta. 